\title{
The UCD experience with classic gastric emptying scintigraphy-systematic review and meta-analysis
}

\author{
Kuo J onathan, Foster Cameron, Shelton David K \\ Department of Nuclear Medicine, UC Davis, CA, USA. \\ Correspondence: J onathan Kuo. Address: Department of Nuclear Medicine, UC Davis. 2315 Stockton Blvd, Sacramento, \\ CA, USA 95817. Telephone: 01-916-703-2273. Fax: 01-916-703-2274. Email: jonathan.kuo@ucdmc.ucdavis.edu \\ Received: October 16, 2011 \\ Accepted: November 18, 2011 \\ Published: December 1, 2011 \\ DOI : $10.5430 / j b g c . v 1 n 1 p 10$ \\ URL: http://dx.doi.org/10.5430/jbgc.v1n1p10
}

\section{Abstract}

Objective: Gastric emptying scintigraphy (GES) is the gold standard for diagnosing gastroparesis. We retrospectively evaluate the largest number of GES at a single institute and assess gastric emptying half-time $\left(\mathrm{T}_{50}\right)$ as a function of patient clinical history.

Method: 515 solid GES were performed. After consumption of Tc-99m albumin colloid, anterior and posterior images were acquired in 15 minutes intervals for at least 90 minutes. The half-time was interpolated and compared with the patient clinical history.

Results: The average normal $T_{50}$ at our institute was 72.8 minutes \pm 50.2 minutes. $T_{50}$ increased in patients with a medical history of diabetes $(p<0.042)$, hiatal hernia, gastrointestinal obstruction, esophagitis, malnutrition, and use of narcotics $(p<0.003)$.

Conclusion: The $T_{50}$ is a practical and objective value for diagnosing gastroparesis, which is associated with several medical disorders that physicians should be aware of.

\section{Key words}

Gastroparesis, Gastrointestinal transit, Gastric emptying/Drug effects, Radiopharmaceuticals/Diagnostic use

\section{I ntroduction}

Gastroparesis is a delayed gastric emptying in the absence of mechanical obstruction. Although commonly associated with nausea and vomiting, these symptoms may or may not be present with gastro paresis. Some studies have shown poor correlation between gastroparesis and the severity of gastric symptoms which include nausea, vomiting, early satiety, postprandial fullness, and abdominal discomfort. It is not a well-documented disease yet highly prevalent [1]. Gastroparesis is found in $30-70 \%$ of patients with dyspepsia and occurs in $20-40 \%$ of diabetic patients. If diagnosed properly and subsequently treated, patients may benefit symptomatically from pharmacologic stimulation [2-4]. 
Before the standard gastric emptying protocol was proposed, each hospital had to have its own protocol along with its own normal value. One algorithm for determining gastroparesis was to measure the gastric half emptying time $\left(T_{50}\right)$, the number of minutes from intake of food until half the food has passed the stomach. If the $T_{50}$ was greater than one standard deviations from the norm, the patient was diagnosed with gastro paresis. Many studies have attempted to establish a universal normal $\mathrm{T}_{50}$, but the challenges faced are:

- Small sample size

- Ethical challenge to administer radioactive material to normal patients

- Poor understanding of gastric physiology

- No established official gastric emptying protocol

- The lack of superior tests to compare with gastric emptying scintigraphy

- $\quad$ Please see Table 1 for a list of normal $\mathrm{T}_{50}$ done by various studies.

Table 1. Gastric Half Emptying times from various studies

\begin{tabular}{lllll}
\hline $\mathbf{T}_{\mathbf{5 0}}(\mathbf{m i n s})^{*}$ & Stdev(mins) $^{*}$ & Sample size & Reference & Comments \\
\hline 75 & 30 & 53 & {$[5]$} & Normal people \\
86 & 14 & 4 & {$[6]$} & Normal people \\
83 & 20 & 123 & {$[3]$} & Normal people \\
78.9 & 21 & 19 & {$[4]^{* *}$} & Normal young adult \\
89.4 & 26 & 37 & {$[7]$} & Normal Jordanians \\
58.3 & 14.7 & 28 & {$[8]^{* * *}$} & Normal adults \\
59.8 & 3.7 & 15 & {$[9]$} & Normal males \\
92.4 & 7.5 & 15 & {$[9]$} & Normal females \\
\hline
\end{tabular}

*Standard deviation of T50

**Egg sandwich

***They used LAO. Ziessman [4] showed no difference between LAO and GM. Used eggs

The summed average $T_{50}$ for 294 normal adults calculated from Table 1 is 79.1 mins \pm 20.6 mins. Disturbances in this time can reveal underlying diseases or functional bowel syndromes leading to the correct treatment. Consequently, we attempt to:

- Determine the normal $T_{50}$ from the largest number of gastric studies in a single institution (Please note that every patient who received GES had some indication for the study. Thus, each patient had suspected gastro paresis. To derive the normal value, we included only patients without any known history that would lead to or was associated with gastro paresis).

- Investigate how $\mathrm{T}_{50}$ can be altered by different underlying diseases, surgeries, body mass index (BMI), age, or solid meal type.

\section{Patients and methods}

\section{Study population}

664 consecutive patients had GES between 2001 and 2006. Liquid studies, reports which lacked gastric emptying time, incomplete studies, and patient refusals were eliminated resulting in 515 solid gastric emptying reports. 318 females and 193 males remained with a total average age of 56.4 years. Indications for gastric emptying included but not limited to emesis, abdominal pain, nausea, bloating, feeling of fullness, early satiety, dyspepsia, abnormal weight loss, diarrhea, constipation, and small intestinal pseudoobstruction. Please see Table 2 for more details. 
Table 2. Summary of patient characteristics

\begin{tabular}{lll}
\hline Characteristic & Value \\
\hline \multirow{6}{*}{ M/F Ratio } & 0.61 \\
Age $(\mathrm{y})$ & $56 \pm 16(10-95)$ \\
BMI $\left(\mathrm{kg} / \mathrm{m}^{2}\right)$ & $30 \pm 8(13-66)$ \\
Diabetes & 124 \\
& GERD & 94 \\
& Dyskinesia & 18 \\
& Surgery & 10 \\
& Hernia & 27 \\
& Nissen's Fundoplication & 17 \\
Gastritis & 12 \\
\hline
\end{tabular}

\section{Acquisition of gastric emptying scintigraphy}

Patients had an overnight (> 6 hours) fast before the morning of the exam. $650 \mu \mathrm{Ci}$ of Tc-99m albumin colloid was bound to 20 grams of liver pate by heating both in a microwave oven for 30-45 seconds on medium. The liver pate was then mixed with 150 grams of Dinty Moore ${ }^{\circledR}$ Beef Stew which was also heated in the microwave. 150 grams of water was also given. This standard meal was used because it is well-known and has been properly evaluated for GES [5, 10]. Liquid gastric emptying tests were not included in our report because liquid meals are poor and unreliable for detecting abnormal gastric emptying [5]. In $<10 \%$ of cases, a different variety of solid protein-based meal was given if the patient could not tolerate the usual regimen. Immediately after quick ingestion of the meal, images were acquired at 15 minute intervals for at least 90 minutes. Large field-of-view $64 \times 64$ gamma camera (Axis Picker) with low energy, all purpose, and parallel-hole collimators was used with a $20 \%$ energy window centered at $140 \mathrm{keV}$.

\section{Analysis of gastric emptying}

Gastric emptying data was decay-corrected to the time when the radiolabeled meal was ingested. Anterior and posterior acquisitions were used to calculate the geometric mean which was then used to generate a time-activity curve. The curve was fitted to an exponential model or a linear model, depending on whichever produced the best approximation based on chi-square test.

Figure 1. This figure shows a series of anterior and posterior acquisitions by 2 separate gamma cameras in 15 minutes intervals

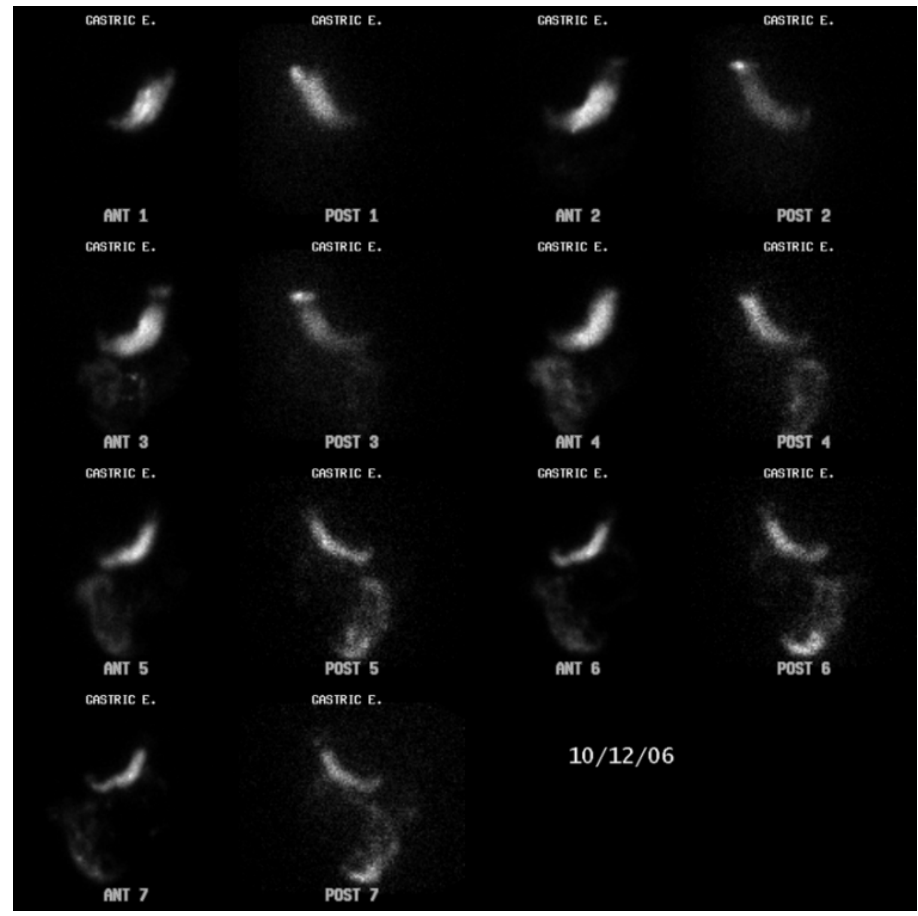

ISSN 1925-4008 E-ISSN 1925-4016 


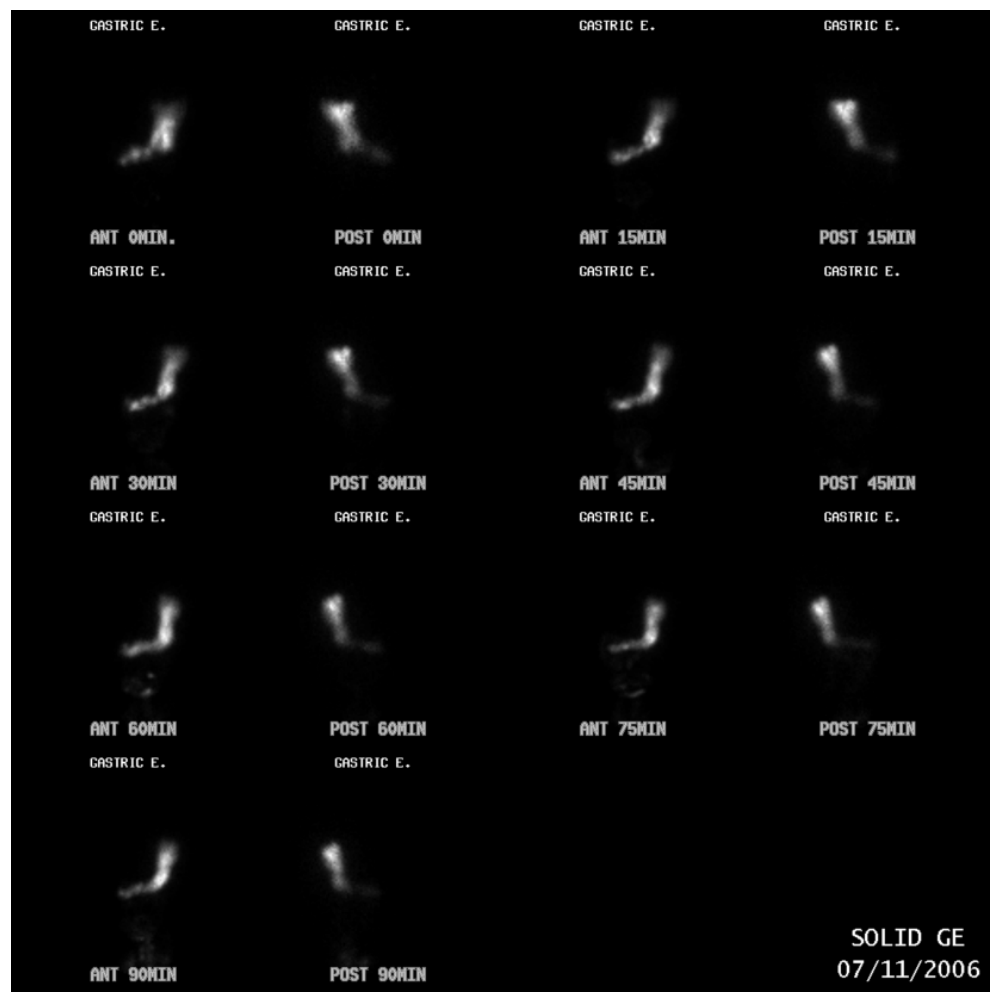

Figure 2. An example of an abnormal gastric emptying exam

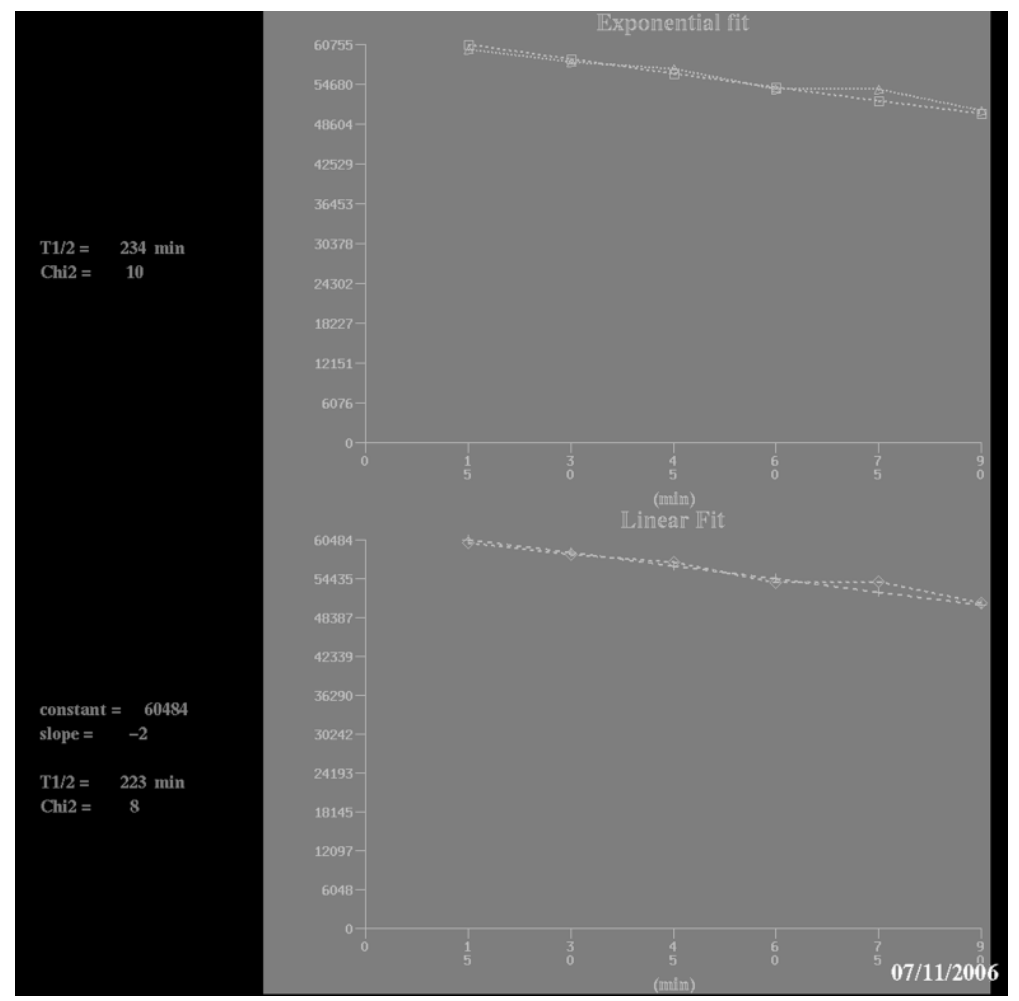

Figure 3. The gastric curve for the patient mentioned in Figure 2. A $\mathrm{T}_{50}$ of 223 minutes indicates that this patient clearly has gastro paresis.

Each patient's past medical history was retrospectively reviewed and analyzed. We also considered age, weight, height, past surgical history, and the indication for exam. Microsoft Excel and The R Project (Version 2.11.0) was used for statistical computing to generate our results. 


\section{Results}

Acquisition of the $T_{50}$ for 515 gastric emptying studies were completed and used to generate a logarithmic histogram of the overall gastric emptying half-time is shown in Figure 4.

Figure 4. Gastric emptying half-time log-scale distribution

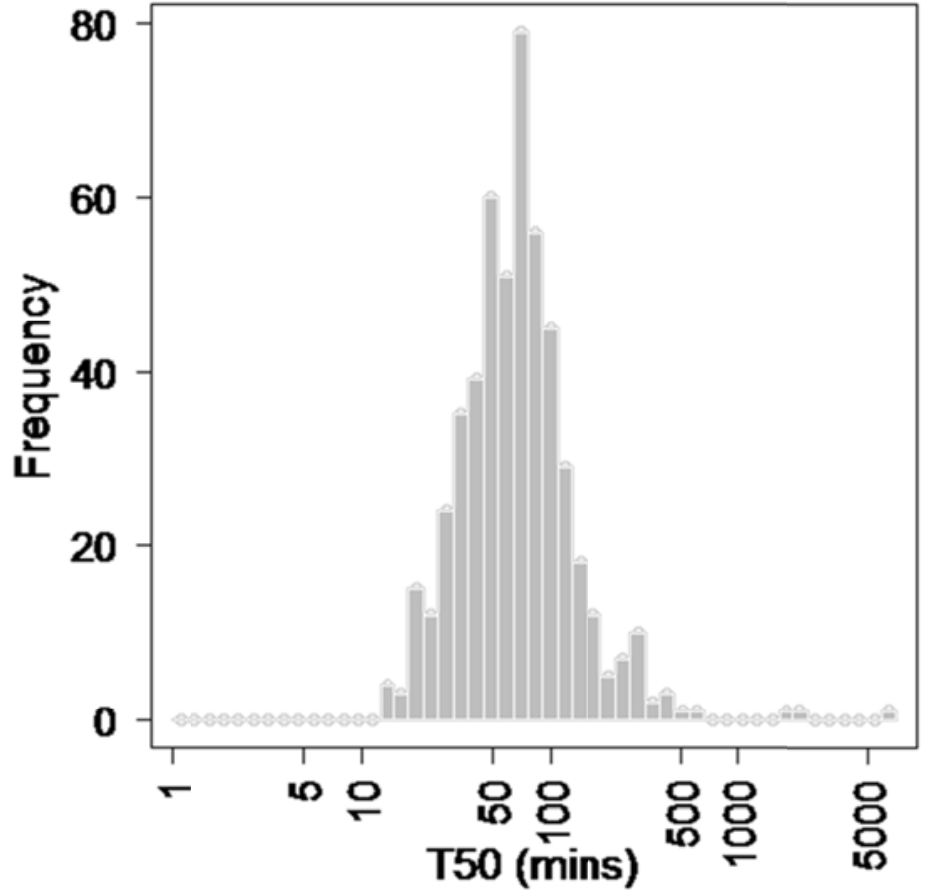

We can clearly see the outliers that are not contiguous with the log-distribution curve. Their $\mathrm{T}_{50}$ is above 1000 minutes. These patients were so gastro paretic, that their extremely high $T_{50}$ would significantly raise the mean $T_{50}$ of a group, and thus abnormally skew our results. From this point onward, these 4 patients will not be included in the following results which will bring down the sample size to 511 .

Table 3 demonstrates that the $\mathrm{T}_{50}$ for both genders are essentially the same. Note that the mean is above our established normal value, because some of these patients do have a diagnosis of gastro paresis.

Table 3. $\mathrm{T}_{50}$ for both genders

\begin{tabular}{llll}
\hline T50 (mins) & Both & Males & Females \\
\hline Mean & 82.8 & 82.2 & 81.6 \\
Standard Deviation & 69.0 & 72.6 & 66.7 \\
Samples & 511 & 193 & 318 \\
\hline
\end{tabular}

A separate group of patients was created without medical history that is suspected to be associated with gastro paresis. Their resulting $\mathrm{T}_{50}$ is indicated in Figure 5 and Table 4. Although gastroparesis may not have been entirely excluded, given the situation, this was the best we could do. Instead of dedicated normal volunteers, all had suspected gastric ailment which warranted the gastric emptying study. Our protocol indicates that the normal $T_{50}$ should be $77 \pm 32$ minutes and the “normal” groups’ average has a similar approximation. 
Figure 5. Boxplot for the "normal" group of patients.

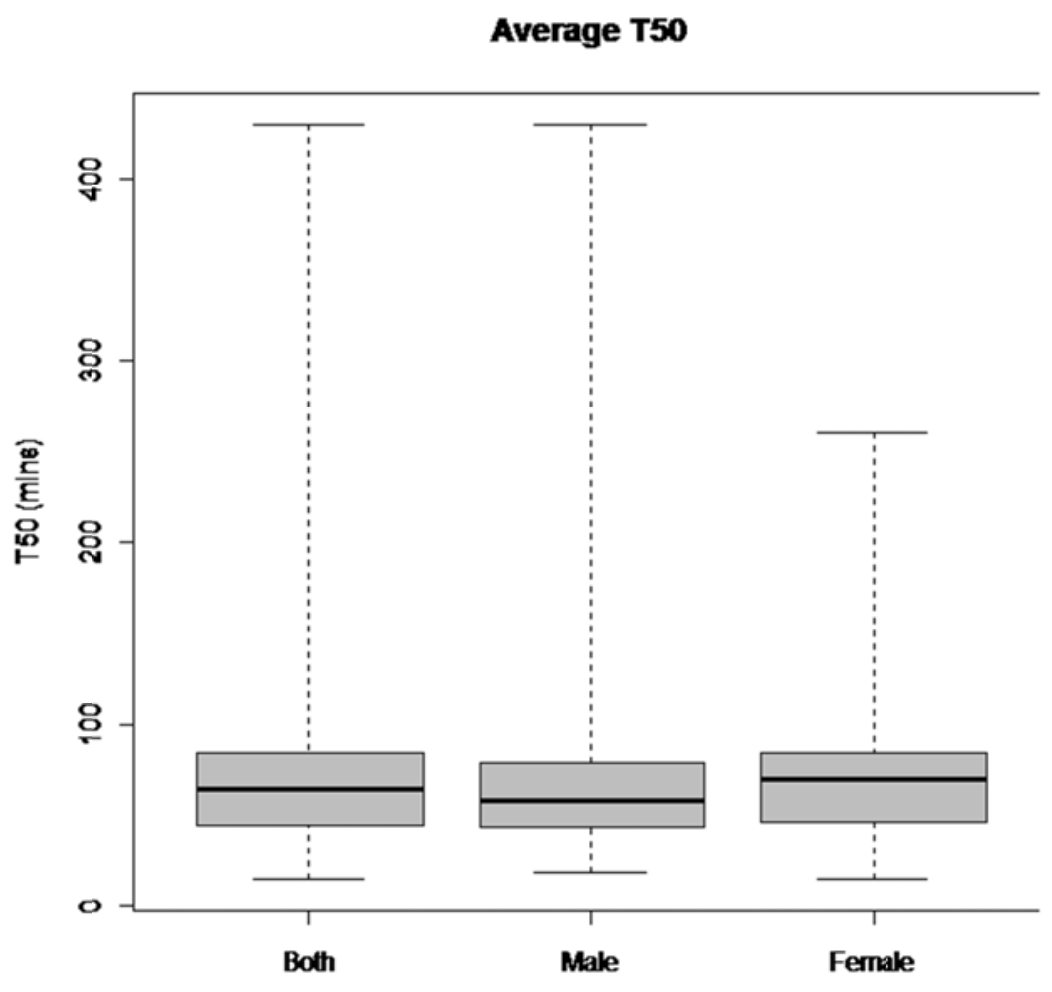

The normal group consists of patients without the following past medical history: metoclopramide use, Diabetes I or II, GERD, Barrett's esophagus, carcinoma, reflux esophagitis, dyskinesia, Parkinson's disease, dysmotility, neuropathy, autonomia, surgery, colectomy, ostomy, laprotomy, ileostomy, adhesion, gastrointestinal obstruction, cholelithiasis, hiatal hernia, pyloric disorders, Nissen's fundoplication, radiation treatment, chemotherapy, narcotic/codeine/morphine /dilaudid/oxycodone use, proton-pump inhibitor use, Sjogren's disease, connective tissue disorder, Raynaud's syndrome, scleroderma, gastritis, irritable bowel syndrome, gastrectomy, vagotomy, paraplegia, Whipple procedure, system lupus erythematous, gastric bypass, and lymphoma.

Table 4. Table of $T_{50}$ for normal patients

\begin{tabular}{llll}
\hline $\mathbf{T}_{\mathbf{5 0}}$ (mins) & Both & Males & Females \\
\hline Median & 64 & 58 & 70 \\
Average & 72.8 & 76.4 & 70.6 \\
StdDev & 50.2 & 67.1 & 36.6 \\
Samples & 213 & 80 & 133 \\
\hline
\end{tabular}

The $p$-value was 0.20 between normal males and normal females. There was no statistically significant difference in gastric emptying between genders still.

In Figure 6, a density scatterplot, we demonstrate the T50 time versus the age of the patients. Older patients tend to have faster gastric emptying time. 
Figure 6. Density scatterplot of $\mathrm{T}_{50}$ in relationship to age. The red line is a linear interpolation of this relationship
T50 versus Age

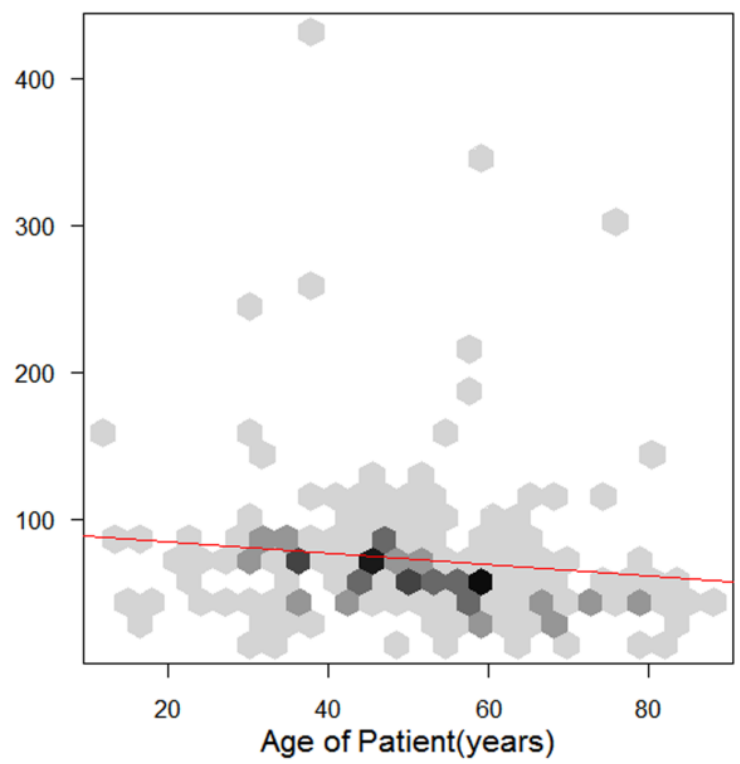

\section{Counts}

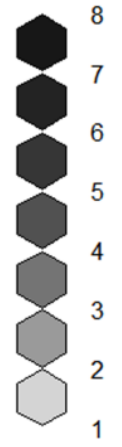

Physicians may want to compensate the patient's age when we calculate the gastric emptying half-time. Our equation for the line of best fit is

$$
\mathrm{T}_{50}=91.25-0.362 \text { (age) }
$$

In Table 5, purely diabetic patients' $\mathrm{T}_{50}$ are compared with normal patients. These patients did not have any of other diseases.

Table 5. Comparison of diabetic and normal patients' $\mathrm{T}_{50}$

\begin{tabular}{lll}
\hline $\mathbf{T}_{\mathbf{5 0}}$ (mins) & Normal & Diabetics only \\
\hline Median & 64 & 66.5 \\
Average & 72.8 & 93.2 \\
StdDev & 50.2 & 97.2 \\
Samples & 213 & 98 \\
\hline Note The diabetic patients must only have diabetes and no other confounding diseases that are associated with gastro paresis &
\end{tabular}

A $t$-test was performed resulting in a two-tailed $P$-value of .042 . Therefore, diabetics had a statistically significantly longer $T_{50}$ than the normal group. Bar graph in Figure 7 shows that diabetics had a noticeably longer gastric emptying half-time. However, there is considerable overlap of timing when both genders are combined and in the males. We are uncertain why diabetes has such a large effect on the $T_{50}$ of females while having a lesser effect on males, but this variation could be attributed to sample size.

Figure 8 demonstrates the prolongation of gastric emptying in underweight patients. Underweight patients are defined as those with a BMI of < 18.5. Normal weighted patients have a BMI between 18.5 and 25. Overweight patients have a BMI between 25 and 30. And obese patients have a BMI $>30$. However, due to small sample size of underweight patients, the difference in half time between the underweight versus normal BMI patients are insignificant. 
Patients who have GERD, in which pharmacologic treatment has failed, undergo Nissen's fundoplication. 24 patients in our institute had this operation followed by a GES. The mean $\mathrm{T}_{50}$ was not statistically significant from a group without any history of gastric surgery.

Figure 7. A comparison of $\mathrm{T}_{50}$ of diabetics with the normal patients. The confidence intervals are set at $95 \%$

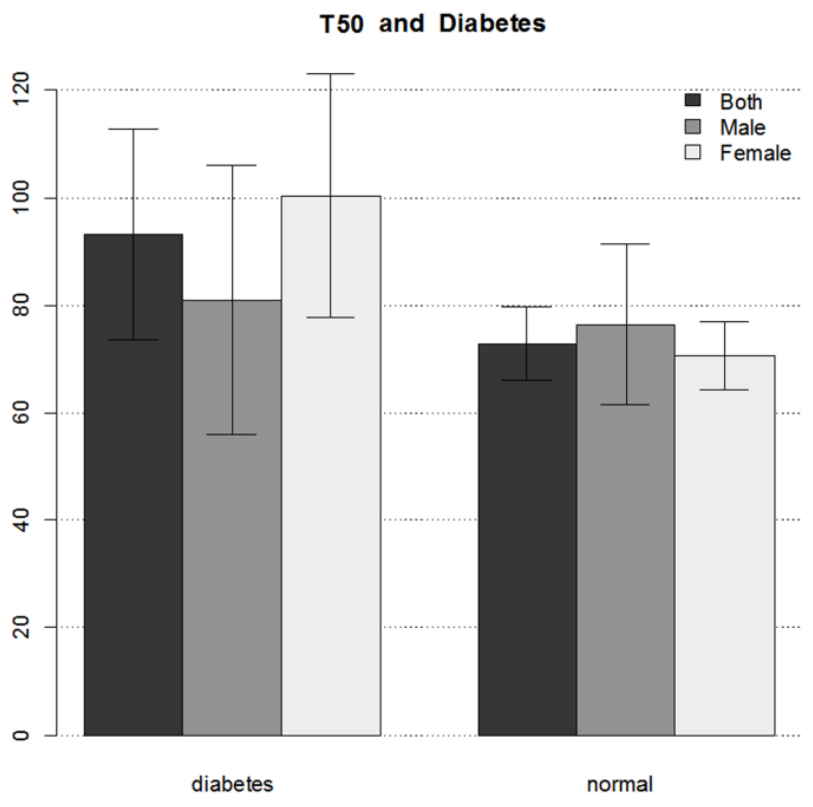

T50 Versus BMI

Figure 8. Average $T_{50}$ versus Body Mass Index

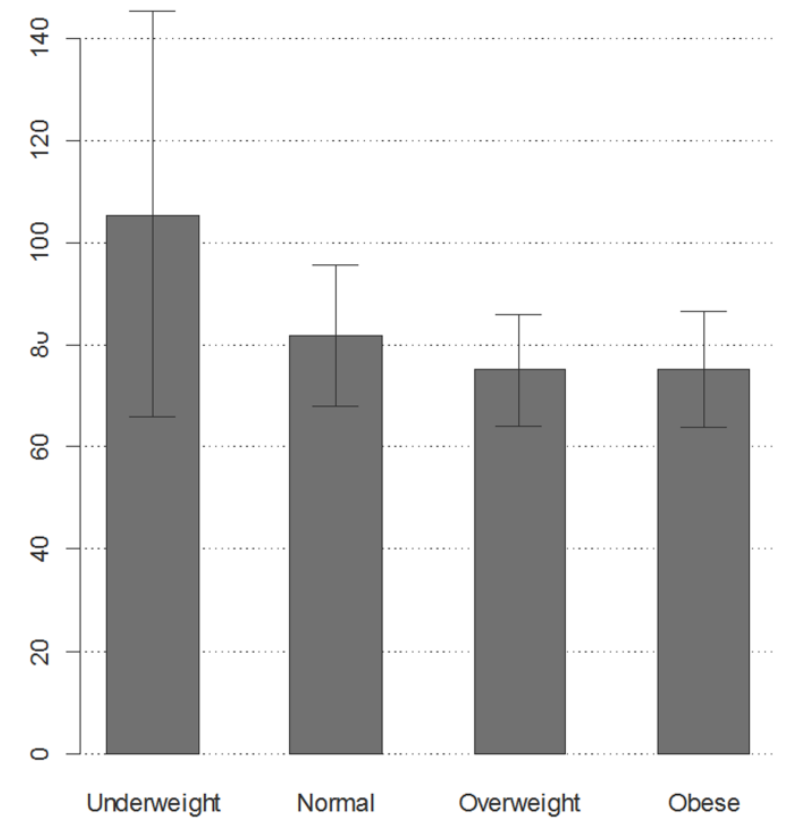

Various other medical disorders and surgical histories were compared with the $T_{50}$ as depicted in Figure 10. Each disorder was exclusive. For example, in the GERD group, each patient must have been diagnosed with GERD and no other diagnosed diseases mentioned below. These diseases were found retrospectively by examining the patient's medical record for diseases that were diagnosed before the GES was performed. Patients with Sjogren's syndrome or 
dysautonomia tended to have rapid gastric emptying. At the other end of the spectrum, patients with a history of gastrointestinal obstruction, hiatal hernia, and esophagitis, on average were found to have gastro paresis.

Figure 9. $\mathrm{T}_{50}$ of patients status post Nissen's Fundoplication versus patients without fundoplication
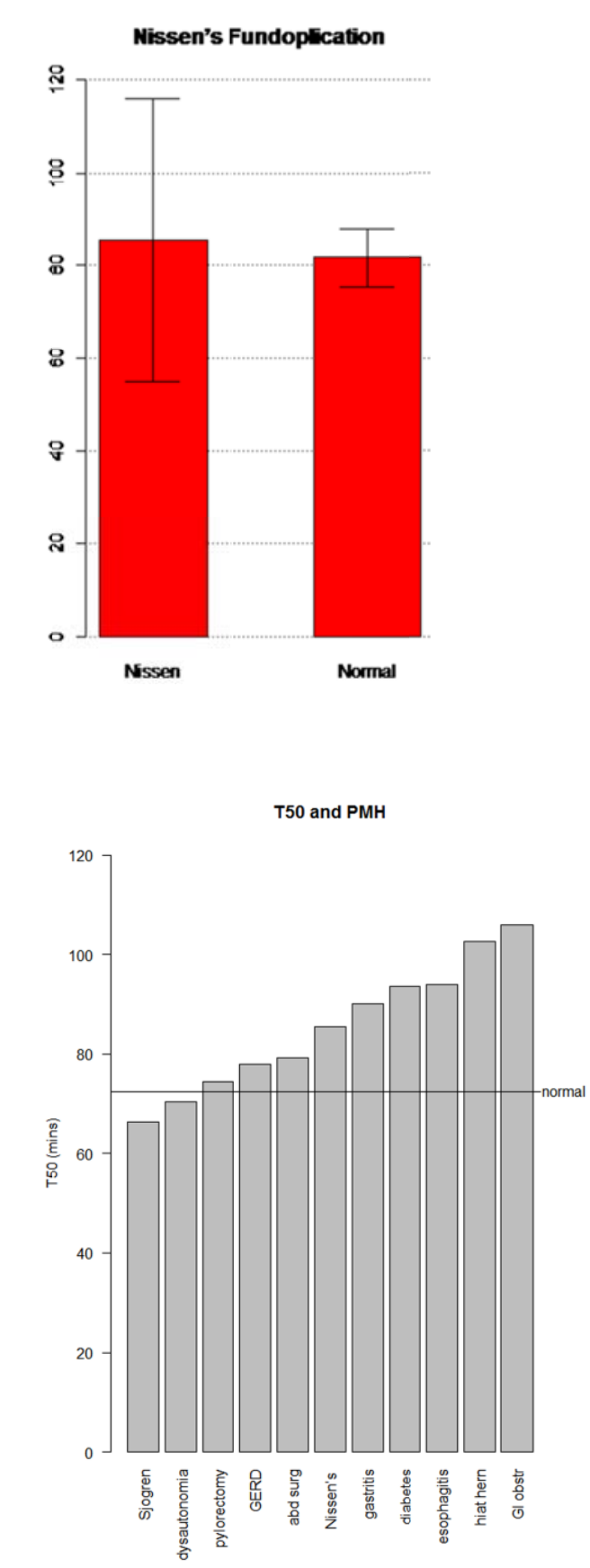

Figure 10. The variation of $T_{50}$ with respect to the past medical histories

Abbreviations: Sjogren group = Sjogren's Syndrome. Pylorectomy = patients who had a pylorectomy in the past. GERD $=$ Gastroesophageal reflux disease. Abd surg $=$ patients who had abdominal surgery in the past. Hiat hern = patients who had an unoperated hiatal hernia in the past. GI obstr = a clinical suspicion of gastrointestinal obstruction. The normal line is marked at 72.8 minutes, the average T50 of a normal patient.

A subset of common drugs was also evaluated in comparison with GES. Figure 11 show that patients with a history of narcotic use had extremely delayed gastric emptying $(p<0.003)$. The narcotics used included codeine, morphine, oxycodone, oxymorphone, and methadone. Patients who had a history of taking proton pump inhibitors (PPI) did not have any significant change in their gastric emptying.

Figure 12 is a bar graph demonstrating the effectiveness of metoclopramide. In our cohort of 23 patients, each patient was diagnosed with gastroparesis as demonstrated by the darker gray bars. On the same day of gastric emptying, each 
patient was given a $10 \mathrm{mg}$ dose of metoclopramide and the gastric emptying study was repeated. The lighter gray bars show the reduction of gastric half emptying time for each patient respectively. On average, metoclopramide reduced gastric emptying half-time by $74 \%$ or 127.8 minutes. Metoclopramide significantly reduces $T_{50}(p<0.0005)$.

Figure 11. $\mathrm{T}_{50}$ as a function of narcotics and proton pump inhibitor (PPI)

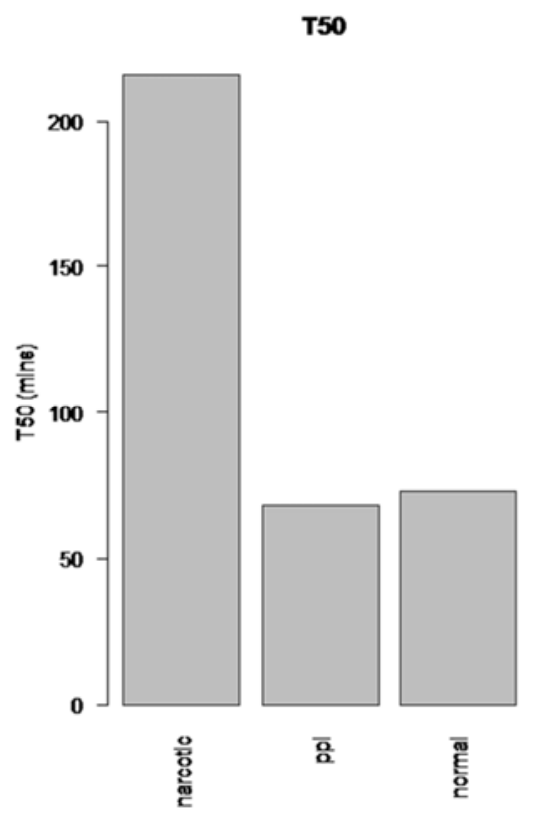

Figure 12. A comparison of $T_{50}$ before and after administration of metoclopramide. The darker bar represents the $T_{50}$ of a patient who is diagnosed with gastro paresis. The lighter bar directly in front of darker bar is the $T_{50}$ of the same patient after taking metoclopramide

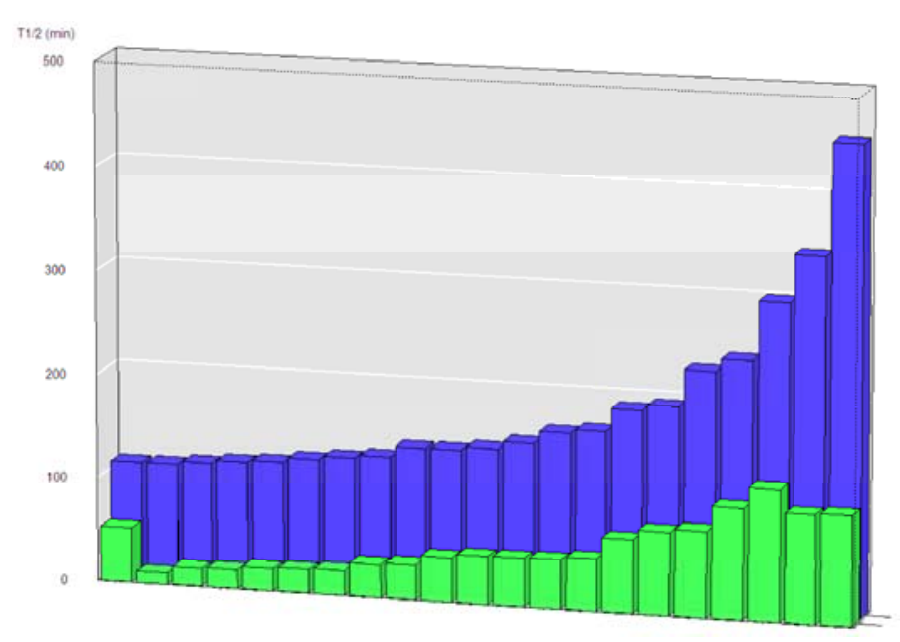

\section{Discussion}

Gastric emptying scintigraphy (GES) is a gold standard for evaluating gastric emptying. $T_{50}$ is a simple approach to interpreting gastric emptying data. It is defined as the time at which $50 \%$ of the meal remains in the stomach after meal ingestion [1]. Except for very prolonged gastro paresis, the half-emptying time provides a quick and simple overview of the whole gastric emptying process [5]. The advantages of GES when compared to other modalities include the following:

- Ultrasound is operator-dependent and requires geometric assumptions.

- B-octonoic acid breath test assumes normal small bowel absorption.

- Acetaminophen absorption also requires normal small bowel absorption. 
However, interpretation of $T_{50}$ in GES is sometimes unclear. The wide variation of reported rates of emptying are due to different protocols, and some centers use two standard deviations rather than one [2] for defining gastro paresis. There has been an attempt to standardize the exam and it is outlined in SNM [2]. However, all the GES investigated in this study were performed before the guidelines were published.

Results of this study demonstrate that the $T_{50}$ for patients without a past medical history of diseases associated with gastroparesis was 72.8 minutes. We consider that group the normal patients. Although our sample size is the largest known for any gastric emptying article currently, we also have an unfavorably large standard deviation (Table 4). This is because some patients had gastroparesis without any medical histories that would lead to gastro paresis. Also, the patient could have had additional gastric related diseases diagnosed after the gastric emptying exam. Interestingly, the distribution of $\mathrm{T}_{50}$ follows a log-scale. Gastric emptying time may lengthen exponentially in gastro paresis.

\section{Prevalence}

It is estimated that $20 \%$ of the population will have significant UGI symptoms. In 146 patients who were diagnosed with gastro paresis, 36\% were idiopathic. 29\% were diabetic, and $13 \%$ had abdominal surgery [14]. Myenteric hypogangliosis has been proposed as a possible cause of idiopathic hypogangliosis. Biopsies have been performed and found that the Cajal cells, pacemaker cells of the GI tract, are reduced leading to slower gastric waveforms. Gastroparesis has been associated with other gastrointestinal diseases including gastro esophageal reflux disease, chronic intestinal pseudo-obstruction, achalasia, celiac disease, atrophic gastritis, peptic ulcer disease and chronic pancreatitis [14].

\section{$T_{50}$ and Gender}

Studies have been conflicted with this association. In a study [15] of 172 patients, gastroparesis was weakly correlated with gender (OR of 1.47). In study [7], female volunteers tended to have slower gastric emptying compared to male subjects, but this was not statistically significant. Another study confirmed that females also had slower gastric emptying [9]. The slower emptying is probably related to hormonal effects or progesterone which reduced contractile responses of the GI smooth muscles. In the Tougas study [3], women had greater percent residual than men in the 1st and 2nd hour. A small study [16] tried to quantify the effects of age using the more traditional gastric emptying protocol with oatmeal, and they found a longer gastric emptying time in women than in men, but the trend was not significant. Our study did not find a statistically significant difference in the $T_{50}$ between genders (Table 4). Females tend to have slower gastric emptying than males but the difference is not significant.

\section{$T_{50}$ and Age}

In a study [15] of 172 patients, gastroparesis was strongly correlated with age greater 50 years with an OR of 3.43. The Tougas study also found that gastric emptying time lengthened with increasing age [3]. However, another study [16] tried to quantify the effects of age using the more traditional gastric emptying protocol with oatmeal. They found that for each additional 20 years of age, there was a 12 minute decrease in gastric emptying time. Our study also found the same correlation but for each additional 20 years, there was only a 7.2 minute decrease in $\mathrm{T}_{50}$. Age may play a major factor in gastric emptying. But since there's no clear directionality, physicians can probably ignore age when interpreting $T_{50}$ for now. More research needs to be done.

\section{$T_{50}$ and Diabetics}

Upper GI symptoms of nausea, vomiting, or early satiety are present in almost a third of patient with type I or II diabetes. Furthermore, gastroparesis is present in $25-55 \%$ of patients with type I diabetes and $30 \%$ of patients with type II diabetes. In a study [15] of 172 patients with upper GI symptoms, Gumaste et al. defined delayed gastric emptying as having a $T_{50}$ of $>90$ mins. Out of the 73 patients with type II diabetes, 42 had evidence of gastro paresis. After adjusting for age, gender, medication, they determined that diabetes was not an independent determinant of gastroparesis in symptomatic patients [15]. Thus, although physicians commonly assume that diabetics with upper GI symptoms are 
more likely to have gastro paresis, this study demonstrates that no correlation between gastroparesis and diabetes. However, a weakness in this study was the use of anterior acquisitions only.

A review [17] of diabetic gastric emptying explains the reason for the apparent lack of correlation between diabetic gastroparesis and symptoms. The functional delay in gastric emptying occurs in settings of significant hyperglycemia. Our study did find a significant difference in the $T_{50}$ of diabetics and patients without any diseases associated with gastroparesis Figure 7. However, we did not measure blood glucose at the time of the exam.

\section{$T_{50}$ and $B M I$}

In a study [7], the $\mathrm{T}_{50}$ did not change significantly for patients with BMI below and above 25. The Tougas study [3] also did not find a correlation. This was further confirmed with another study [19] using a 3 hour gastric emptying protocol to compare obese (mean BMI 38.7) and normal weight males. They found no difference in the half-time even when the obese patients had major weight loss. However, the emptying rate within the first 30 minutes in obese subjects is faster than in lean subjects. Our results (Figure 8) were consistent with the other studies. No significant difference between underweight, normal, and obese patients were found.

Note however that the average underweight's $T_{50}$ was diagnostically gastro paretic. Underweight patients may have developed chronic malnutrition which led to poor neuromuscular gastric performance. In another study, there was a significant delay in gastric emptying involving $80 \%$ of the 16 anorexia nervosa patients compared with 13 normal controls [18]. They concluded that body size itself is not a factor of gastric emptying but malnutrition is. The association was further strengthened by another study involving anorexia nervosa patients who had BMI between 11 and 18 . Interestingly, gastric emptying time normalized for patients who received enteral feeding treatment yet still had a BMI < 18 [20].

\section{$\mathbf{T}_{50}$ and Nissen Fundoplication}

Patients who have received laparoscopic or open Nissen fundoplication have no statistically significant change in gastric emptying time compared with normal controls [21]. Interestingly, gastric emptying is slightly slower preoperatively but postoperatively faster, approaching the $T_{50}$ of normal un-operated patients controls [21]. In another study, the gastric emptying rate is prolonged for those who still had reflux symptoms after Nissen fundoplication [22]. Although none of our patients had a partial (Toupet) fundoplication, a study involving 106 patients with Toupet fundoplication did not show statistically significant changes in gastric emptying time after the operation [23]. Gastric emptying scintigraphy was also found to poorly correlate with postoperative symptoms which may be from iatrogenic or related to vagal denervation. We found that our cohort of patients who have had a Nissen's fundoplication did not have a significantly different $T_{50}$ from those who did not have Nissen's fundoplication. Still, nuclear scintigraphy may provide important objective information regarding motility problems in the setting of a fundoplication.

\section{$\mathbf{T}_{50}$ compared with various diseases}

There are few published studies that report the variation of $T_{50}$ with respect to multiple diseases. We found some trends between common diseases in our patients' past medical histories, but to prove if there were actual correlations is beyond the scope of this study. The most common diseases were listed in Figure 10. Patients with Sjogren's syndrome or dysautonomia had relatively more rapid gastric emptying which may be secondary to damage of the vagal nerve. However, a study of 28 patients [24] showed that patients with Sjogren's syndrome, in fact, had statistically significant gastro paresis. We also do not know whether the diseases cause gastroparesis or if gastroparesis causes the disease. Perhaps esophagitis was secondary to gastroparesis because of the prolonged presence of food in the stomach.

\section{$T_{50}$ and Drugs}

Metoclopramide is a 5-HT4 agonist that causes prokinectic activity and antiemetic effect. It also increases the esophageal sphincter and fundal tone. Studies have shown its alleviation for idiopathic or diabetic gastroparesis [14]. In 
a small study of 11 patients with gastro paresis, $10 \mathrm{mg}$ of intramuscular metoclopramide significantly reduced gastric emptying time from 60 to 120 minutes [18]. Our study also found that metoclopramide was an effective agent for reducing gastric emptying time (Figure 12) by an average of 128 minutes. Other drugs that may be used to treat gastroparesis include erythromycin, botox, and cisapride.

We also found that narcotics significantly lengthened gastric emptying, which is well-known. However, the effect of proton pump inhibitors are studied less. In our study, PPI's did not have any detectable effect on gastric function (Figure $11)$.

\section{Limitations}

There are a few limitations in our study that are worth mentioning. First, the patients undergoing this study all had suspicion of gastro paresis. There are no completely normal patients in our study so our normal $T_{50}$ is only a subset of patients without a clinical history of gastroparesis or diseases associated with gastroparesis (Figure 5). Our software did not have a sigmoidal trend-fitting algorithm which may or may not have a better fit with our emptying curves. We also did not have the length of time between diagnosis of diabetes and the date of the gastric emptying study. We suspect that having uncontrolled diabetes for many years may cause neuromuscular damage leading to gastro paresis. The duration of gastric emptying may increase directly in relationship to the duration of diabetes. The patient history could have been missing diseases that were discovered after the gastric emptying study.

\section{Conclusion}

We have conducted a gastric emptying study involving the single largest number of GES known to us to this date. We have found that the $\mathrm{T}_{50}$ for patients without any history of diseases known to associate with gastroparesis was $72.8 \pm$ 50.2 minutes.

- $\mathrm{T}_{50}$ increased significantly when the patient was diabetic or was taking narcotics.

- $\mathrm{T}_{50}$ was inversely correlated with age and increased for patients with a BMI of $<18.5$.

- $\mathrm{T}_{50}$ did not change significantly with different genders, after Nissen’s fundoplication, or with PPIs.

The new standardized protocol for gastric emptying scintigraphy requires 4 hours and may not be practical for all institutions. For those who prefer a shorter acquisition, we hope that our $\mathrm{T}_{50}$ will be useful for your studies. In the near future, we will address our experience with the new 4-hour protocol and its utility in a large academic institute.

\section{Disclosure of potential conflicts and interest}

The authors declare that they have no conflict of interest

\section{References}

[1] Maurer AH, Parkman HP Update on gastrointestinal scintigraphy, in: Seminars in Nuclear Medicine. 2006;110.

[2] Abell TL, Camilleri M, Donohoe K, Hasler WL, Lin HC, Maurer AH, McCallum RW, Nowak T, Nusynowitz ML, Parkman HP, others (2008) Consensus recommendations for gastric emptying scintigraphy: a joint report of the American

Neurogastroenterology and Motility Society and the Society of Nuclear Medicine. Journal of Nuclear Medicine Technology. 36(1):44. PMid: 18287197. http://dx.doi.org/10.2967/jnmt.107.048116

[3] Tougas G, Eaker EY, Abell TL, Abrahamsson H, Boivin M, Chen J, Hocking MP, Quigley EMM, Koch KL, Tokayer AZ, others (2000) Assessment of gastric emptying using a low fat meal: establishment of international control values. The American Journal of Gastroenterology. 95(6):1456-62. PMid: 10894578. http://dx.doi.org/10.1111/j.1572-0241.2000.02076.x

[4] Ziessman HA, Fahey FH, Atkins FB, Tall J (2004) Standardization and quantification of radionuclide solid gastric-emptying studies. J. Nucl. Med. 45(5):760-64. PMid: 15136623. 
[5] Le Roux PY, Bouchet F, Querellou S, Vervueren L, Lacoeuille F, Turzo A, Salaun PY, Couturier OF (2011) American consensus recommendations for gastric scintigraphy: curve fitting with only a few points remains an easy and accurate method to obtain reliable and reproducible gastric emptying estimates. Nuclear Medicine Communications. 32(1):30. PMid: 21042226. http://dx.doi.org/10.1097/MNM.0b013e3283404270

[6] Elashoff JD, Reedy TJ, Meyer JH (1982) Analysis of gastric emptying data. Gastroenterology 83(6):1306. PMid: 7129034.

[7] Sneineh A, AlSharif A, Khatib M, Shennak M, Chakik R, Al-Huniti N (2010) Assessment of Gastric Emptying in Normal Jordanian Individuals. Journal of the Bahrain Medical Society. 22(2):60-64.

[8] Rahim MK, Durr-e-Sabih, Mateen A, Najam-Uddin, Yousaf M (2007) Studies of gastric emptying time in patients with non-ulcer dyspepsia. Nuclear Medicine Communications. 28(11):852-58. PMid: 17901768. http://dx.doi.org/10.1097/MNM.0b013e3282f0d167

[9] Datz FL, Christian PE, Moore J (1987) Gender-Related Differences in Gastric Emptying. J Nucl Med. 28(7):1204-07. PMid: 3598704.

[10] Camilleri M, Zinsmeister AR, Greydanus MP, Brown ML, Proano M (1991) Towards a less costly but accurate test of gastric emptying and small bowel transit. Digestive Diseases and Sciences. 36(5):609-15. PMid: 2022162. http://dx.doi.org/10.1007/BF01297027

[11] Guo J-P, Maurer AH, Fisher RS, Parkman HP (2001) Extending Gastric Emptying Scintigraphy from Two to Four Hours Detects More Patients with Gastroparesis. Digestive Diseases and Sciences. 46(1):24-29. PMid: 11270790. http://dx.doi.org/10.1023/A:1005697422454

[12] Nusynowitz ML (2008) Comments regarding “consensus recommendations for gastric emptying scintigraphy.”Am. J. Gastroenterol. 103(12):3217.

[13] Weinman J, Gritter K (2006) Gastric emptying: Normal values for a simple solid meal. J Nucl Med Meeting Abstracts 47:335P

[14] Patrick A, Epstein O (2008) Review article: gastroparesis. Alimentary Pharmacology \& Therapeutics. 27(9):724-40. http://dx.doi.org/10.1111/j.1365-2036.2008.03637.x

[15] Gumaste VV, Egbuna I, Goldman A (2010) Diabetes is Not an Independent Predictor of Gastroparesis in Symptomatic Patients Referred for Gastric Emptying Studies. J Gastrointestin Liver Dis. 19(1):37-42. PMid: 20361073.

[16] Klingensmith WC, Rhea KL, Wainwright EA, Hopper OW (2010) The Gastric Emptying Study with Oatmeal: Reference Range and Reproducibility as a Function of Age and Sex. J Nucl Med Technol. 38(4):186-90. PMid: 21078783. http://dx.doi.org/10.2967/jnmt.110.077065

[17] Samsom M, Bharucha A, Gerich JE, Herrmann K, Limmer J, Linke R, Maggs D, Schirra J, Vella A, Wlörle HJ, others (2009) Diabetes mellitus and gastric emptying: questions and issues in clinical practice. Diabetes/metabolism Research and Reviews. 25(6):502-14. PMid: 19610128. http://dx.doi.org/10.1002/dmrr.974

[18] McCallum RW, Grill BB, Lange R, Planky M, Glass EE, Greenfeld DG (1985) Definition of a gastric emptying abnormality in patients with anorexia nervosa. Digest Dis Sci. 30(8):713-22. PMid: 4017831. http://dx.doi.org/10.1007/BF01320484

[19] Verdich C, Madsen J, Toubro S, Buemann B, Holst J, Astrup A (2000) Effect of obesity and major weight reduction on gastric emptying. International Journal of Obesity. 24:899-905. PMid: 10918538. http://dx.doi.org/10.1038/sj.ijo.0801250

[20] Szmukler GI, Young GP, Lichtenstein M, Andrews JT (1990) A serial study of gastric emptying in anorexia nervosa and bulimia. Australian and New Zealand Journal of Medicine. 20(3):220-25. PMid: 2372271. http://dx.doi.org/10.1111/j.1445-5994.1990.tb01023.x

[21] Saali K, Koskinen M, Karhumaki L, Kossi J, Luostarinen M, Teerenhovi O, Isolauri J, Viljakka M (1999) Antireflux Surgery Enhances Gastric Emptying. Arch Surg. 134(1):18-21. PMid: 9927124. http://dx.doi.org/10.1001/archsurg.134.1.18

[22] Maddern GJ, Jamieson GG, Chatterton BE, Collins PJ (1985) Is there an association between failed antireflux procedures and delayed gastric emptying? Ann. Surg. 202(2):162-65. PMid: 4015221. http://dx.doi.org/10.1097/00000658-198508000-00005

[23] Schuchert MJ, Pettiford BL, Abbas G, Oostdyk A, Landreneau JR, Kilic A, Landreneau JP, Luketich JD, Landreneau RJ (2010) The use of esophageal transit and gastric emptying studies in the evaluation of patients undergoing laparoscopic fundoplication. Surg Endosc. 24(12):3119-26. PMid: 20490564.

[24] HAMMAR O, OHLSSON B, WOLLMER P, MANDL T (2010) Impaired Gastric Emptying in Primary Sjögren’s Syndrome. The Journal of Rheumatology. 37(11):2313-18. 